\title{
A Study on Factors that may affect the Oral Health Status of University Students
}

\author{
Hye-Jung Jin ${ }^{1}$, Min-Kyung Lee ${ }^{2 *}$ \\ ${ }^{I}$ Dept. of Dental Hygiene, Yeungnam University College, Daegu, 42415, KOREA \\ ${ }^{2}$ Dept. of Dental Hygiene, Dong-Eui University, Busan, 47340, KOREA
}

\begin{abstract}
The present study investigated and analyzed how dietary habits, snack intake behavior, and stress affect the subjective oral health status of university students. Subject data involved oral health status and oral health awareness inquires via survey inquiries and the SPSS 20.0 statistics program. The results of the study are as follows. Snack intake increases when stress increases, and this affects oral health. Furthermore, nutrition labeling awareness increases when stress is lower and dietary habits are better, which affects oral health status. College is a transitional period between adolescence and adulthood, when adequate intake of nutrition and establishing proper dietary habits are important. University students may establish different dietary habits from adolescence due to the sudden change in environment, so by actively using nutrition labels, they can choose foods that fit their oral health status and needs, and the adequate education for filling in the lacking nutrients is important. The oral health awareness and behavior of university students appear to have difference in accordance with the general characteristics of subjects, and oral health education must consider such differences. Because awareness toward oral knowledge and oral education is low, education corresponding to this must be strengthened. The present study investigates the effect of dietary habits, snack intake behavior, and stress on subjective oral health status in order to provide basic data necessary in building programs for increasing preventive oral health management behaviors.
\end{abstract}

Keywords: Dietary Habits, Snack Types, Stress, Subjective Oral Status

\section{Introduction}

University students easily lose stability in their dietary life due to irregular meals, meager breakfasts, inadequate snacks, eating out, over eating, and excessive drinking, all of which result from the sudden outbreak of free time. With limited finances, students are unaware of adequate foods for maintaining health and depend mainly on cheap convenience foods or foods that may be eaten with simple beverages, and hence, they are unable to eat foods that supply the basic nutrients. In particular, snacks are for the sufficient intake of nutrients lacking in regular meals and must be foods that are low in satiety, stay a short time in the stomach and are balanced in nutrition. However, in reality, frequent snack intakes disrupt the next meal and hinder a balanced intake of three meals a day so that meal times and portions become irregular, increasing the intake amount and frequency of snacks1). Thanks to the rapid advancement in economic development since the 1960s, the standard of living in Korea has improved greatly, but this has also brought about much negative change which includes the increase in sugar intake and frequency. Wrong dietary habits due to convenience oriented dietary living causes an imbalance in nutrients in adulthood, and increases the occurrence frequency of dental caries. These periods when subjects first make entry into the procession of adults are filled with social and mental stress which causes negative emotional reactions with pressure and successive tension amidst rapidly changing social phenomena. Stress is known to negative effect human both physically and psychologically, and can cause psychological effects like reduced concentration, anxiety, sleep disorders, and hostility and emotional maladjustments effects like frustration, anger, and dissatisfaction, which can ultimately be the cause of chronic adult diseases. Daily occurring stress is reported to lower the level of immunity. Nevertheless, most university students are not interested in health issues because they are young and are unaware of the importance of taking in balanced nutrition. Furthermore, university students often get knowledge and information on nutrition through mass media including TV, radio, newspapers, magazines, and the internet, and these routes often prove to be strongly commercial and insufficient in terms of scientific bases. By inducing uncritical blind faith and insolvency toward wrong information, they may have an adverse effect that rather hinders sound dietary living. College is a transitional period around 20 years old and may be viewed as the last period possible of correcting dietary habits before adulthood. In other words, the dietary habits of university students form the dietary habits that are to be settled in the next stage of adulthood, so much effort must be exerted to form the correct dietary habits2).

The mouth especially plays the most fundamental role in maintaining the health of the other organs of the body. Humans must take in food in order to survive and a balanced intake of food is closely related to not only oral health but also health in general. Stress is also related to oral health3). 
Therefore, the present study investigates the stress, dietary habits, food intake frequencies, and oral health of university students and analyzes their interconnectivity to reduce stress and provide basic data that maintains and improves oral health via dietary control.

\subsection{Research Subjects}

\section{Method}

The research subjects of the present study were 1,2,3,4 year students at a university in the Yeongnam region and were selected by a convenience sampling method. The survey used in the study was ultimately completed by revising and supplementing questions that were difficult to understand after conducting a preliminary inquiry on 30 students at $\mathrm{K}$ university in the Yeongnam area, with the purpose of confirming the suitability and validity of the survey via preceding research. The response results of 400 subjects were used in the final analysis after excluding 20 surveys with insincere answers.

\subsection{Measurement Tools}

The tools used in the present study were structuralized surveys. The preliminary inquiry was conducted on 30 students at Y University in Daegu. The results enabled the questions to be rewritten and revised in terms of configuration4)5), which is as follows.

1) Subjective well-being(5 questions)

2) Stress measurement (23 questions)

3) Knowledge of oral health(20 questions)

4) Oral health status(15 questions)

5) Dietary life habits (6 questions on dietary habits, 12 questions on snack intake conditions, 8 questions on nutrition label awareness, and 6 questions on purchase behavior regarding nutrition labels)

6) Sociodemographic characteristics included gender, age, department, grade, residential type, allowance, and family members(7 questions).

Results of analyzing Cronbach's alpha in order to verify the reliability of the tools used in the study revealed Cronbach's a score for subjective well-being to be 0.82 , Cronbach's a score for stress measurement to be 0.91 , and Cronbach's a score for knowledge regarding oral health to be 0.63 , indicating a relatively high level of reliability secured for the study.

\subsection{Data Analysis}

The study used the SPSS 20.0 statistics program for the collected data in order to examine the effect of dietary habits, snack intake forms, and stress on subjective oral health status. The study conducted frequency analysis by frequency and percentage in order to find out the general characteristics of the research subjects. In order to investigate differences in subjective well being, stress, oral health status, and dietary life(dietary habits, snack intake, nutrition labels) depending on the general characteristics of the subjects, the study conducted a cross analysis by $\chi^{2}$.verification, an independent sample t-test, and one-way ANOVA, and used the Duncan test for post hoc analysis. In order to inquire into the dietary habits, stress and oral health status of university students, the study conducted correlation analysis. In order to inquire into the effect of university student dietary life and stress on oral health status, the study conducted multiple regression analysis.

\section{Results}

The frequency analysis on the general characteristics of the subjects are indicated by $\langle$ Table 1$\rangle$. <Table 1> General Characteristics of the Research Subjects

\begin{tabular}{|l|l|l|l|}
\hline Categories & Male & $\mathrm{N}$ & $\%$ \\
\hline \multirow{4}{*}{ Gender } & Female & 182 & 45.5 \\
\hline \multirow{5}{*}{ Age } & 18 & 218 & 54.5 \\
\cline { 2 - 4 } & 19 & 88 & 22.0 \\
\cline { 2 - 4 } & 20 & 156 & 39.0 \\
\cline { 2 - 4 } & 21 & 71 & 17.8 \\
\cline { 2 - 4 } & 22 & 38 & 9.5 \\
\cline { 2 - 4 } & 23 and over & 29 & 7.3 \\
\hline \multirow{5}{*}{ Grade } & 1 & 18 & 4.5 \\
\cline { 2 - 4 } & 2 & 264 & 66.0 \\
\cline { 2 - 4 } & 3 & 80 & 20.0 \\
\cline { 2 - 4 } & 4 & 42 & 10.5 \\
\hline Residential Type & Home & 14 & 3.5 \\
\cline { 2 - 4 } & Living apart from family & 19 & 10.3 \\
\cline { 2 - 4 } & Boarding House(Dorm) & 335 & 83.8 \\
\cline { 2 - 4 } & Living with relatives & 2 & 0.5 \\
\hline
\end{tabular}


A Study on Factors that may affect the Oral Health Status of University Students

\begin{tabular}{|l|l|l|l|}
\hline & Miscellaneous & 3 & 0.8 \\
\hline \multirow{4}{*}{ Monthly Allowance } & Under 200,000 won & 112 & 28.0 \\
\cline { 2 - 4 } & $210,000-300,000$ & 200 & 50.0 \\
\cline { 2 - 4 } & 310,000 and over & 88 & 22.0 \\
\hline \multirow{4}{*}{ Number of Family Members } & 3 or under & 52 & 13.0 \\
\cline { 2 - 4 } & 4 & 253 & 63.3 \\
\cline { 2 - 4 } & 5 or more & 95 & 23.8 \\
\hline Total & 400 & 100.0 \\
\hline
\end{tabular}

The overall knowledge level of oral health was high, as indicated by $<$ Table $2>$ which states 'When brushing teeth, the tongue must also be brushed,' $(\mathrm{M}=3.95)$ 'Cavities cannot be prevented because they are hereditary,' $(M=3.94)$ and 'No smoking can prevent teeth discoloration, bad breath, and oral cancer.' $(M=3.94)$ The knowledge level was also high in terms of 'Using an electric toothbrush is better than using a manual tooth brush,' $(\mathrm{M}=2.65)$ and 'Xylitol does not help prevent cavities.' $(\mathrm{M}=3.06)$

<Table 2> The overall knowledge level for oral health

\begin{tabular}{|l|l|l|}
\hline Questions & Mean & SD \\
\hline 1. Cavities cannot be prevented because they are hereditary. & 3.94 & .957 \\
\hline 2. Fluorine coating helps prevent cavities. & 3.39 & .889 \\
\hline 3. Three minutes is an adequate amount of time for toothbrushing one time. & 3.68 & .943 \\
\hline 4. The cause of gum disease is plaque(germ lump). & 3.58 & .892 \\
\hline 5. The best method to prevent cavities is toothbrushing. & 3.62 & .940 \\
\hline 6. Scaling(plaque removal) has many side effects like reduced and shaken teeth. & 3.32 & 1.028 \\
\hline 7. It is best to brush your teeth right after a meal. & 3.36 & 1.179 \\
\hline 8. No smoking can prevent teeth discoloration, bad breath, and oral cancer. & 1.117 \\
\hline 9. Bleeding during toothbrushing is a symptom of gum disease. & 3.94 & 1.013 \\
\hline 10. Xylitol does not help prevent cavities. & 3.73 & .972 \\
\hline 11. Using an electric toothbrush is better than using a manual tooth brush. & 3.06 & .985 \\
\hline 12. Fruits, milk and vegetables are foods that clean your teeth. & 2.65 & .990 \\
\hline 13. Tooth brushes with mid sized heads and straight handles are good. & 3.16 & .919 \\
\hline 14. Cavities are unrelated to food because germs cause them. & 3.17 & 1.156 \\
\hline 15. The tongue must also be cleaned when brushing your teeth. & 3.63 & 1.170 \\
\hline 16. Brushing your teeth as hard as you can helps prevent cavities. & 3.95 & 1.097 \\
\hline 17. The greatest reason for brushing your teeth is to prevent bad breath. & 3.49 & 1.063 \\
\hline 18. The use of floss is effective in preventing cavities. & 3.16 & 1.050 \\
\hline 19. Gumdiseases gradually occur and causedamage to the tooth bone structure. & 3.53 & .906 \\
\hline $\begin{array}{l}\text { 20. It is good to use the rotation method(Top to bottom for upper teeth and bottom to } \\
\text { top for lower teeth) when brushing your teeth. }\end{array}$ & 3.55 & 1.056 \\
\hline
\end{tabular}

The correlation between student dietary life and stress on the one hand and oral health status on the other hand. The study conducted correlation analysis in order to investigate the correlation between dietary life and stress on the one hand and oral health status on the other. The results are indicated by $\langle$ Table 3$\rangle$. Subjective well-being had a negative(-) relationship with stress( $\mathrm{r}=-.399, \mathrm{p}<.001)$. In other words, stress was lower when subjective well-being was higher. Stress had a positive $(+)$ relationship with snack intake $(\mathrm{r}=.165, \mathrm{p}<.01)$, and a negative(-) relationship with nutrition label purchase behaviors $(\mathrm{r}=-.109, \mathrm{p}<.05)$ and oral health status $(\mathrm{r}=-.110$, $\mathrm{p}<.05)$. In other words, oral health status worsened when stress and snack intake increased. Nutrition label awareness had a positive(+) relationship with nutrition label purchase behaviors $(r=.202, \mathrm{p}<.001)$ and oral health status(r=.192, $\mathrm{p}<.001)$. In other words, nutrition label purchase behaviors were positive and oral health status was better when nutrition label awareness was higher.

<Table 3> Correlation between sub-variables

\begin{tabular}{|c|c|c|c|c|c|c|}
\hline \multicolumn{2}{|l|}{ Variable } & \multicolumn{2}{|l|}{ Self Identity } & \multirow[t]{2}{*}{ Stress } & \multirow{2}{*}{$\begin{array}{l}\text { School Life } \\
\text { Interpersonal } \\
\text { Relationships }\end{array}$} & \multirow{2}{*}{$\begin{array}{l}\text { Subjective } \\
\text { Oral Health } \\
\text { Oral Health } \\
\text { Status }\end{array}$} \\
\hline & & $\begin{array}{l}\text { Subjective } \\
\text { Well-Being }\end{array}$ & $\begin{array}{l}\text { Self } \\
\text { Concept } \\
\text { Clarity }\end{array}$ & & & \\
\hline \multirow[t]{2}{*}{ Self Identity } & Subjective Well-Being & 1 & & & & \\
\hline & Self Concept Clarity & $-.190^{\text {Fat }}$ & 1 & & & \\
\hline \multicolumn{2}{|l|}{ Stress } & $-.398 * * *$ & $.427^{\text {wetek }}$ & 1 & & \\
\hline School Life & Interpersonal Relationships & $.534^{10 p k}$ & $-.234^{\text {topk }}$ & $-.440^{* * a k}$ & 1 & \\
\hline Subjective Oral Health & Oral Health Status & $.161^{\text {** }}$ & $-.185^{\text {werk }}$ & $-.201^{\text {Note }}$ & $.169^{* 0 \times k}$ & 1 \\
\hline
\end{tabular}

In order to investigate the effect of student dietary living and stress on oral health status, the study conducted regression analysis, the results of which are indicated by $\langle$ Table 4$\rangle$.

The degree of explanatory power in regards to the effect of student dietary life and stress on oral health status was about $6.4 \%$, and the regression model appeared to be significant $(\mathrm{F}=4.454, \mathrm{p}<.001)$. The analysis 
results revealed that $\operatorname{stress}(\beta=-.111, \mathrm{p}<.05)$ had a negative(-) effect on oral health status, while dietary habits $(\xi=.097, \mathrm{p}<.05)$ and nutrition label awareness $(\xi=.193, \mathrm{p}<.05)$ had a positive $(+)$ one. In other words, the oral health status of students was predicted to be better when stress was lower, dietary habits better, and nutrition label awareness higher.

<Table 4> The effect of student dietary life and stress on oral health status

\begin{tabular}{|c|c|c|c|c|c|c|}
\hline Dependent Variable & Independent Variable & $B$ & $S E$ & $G$ & $t$ & $p$ \\
\hline \multirow[t]{7}{*}{ Oral Health Status } & (Constant) & 22.173 & 1.494 & & 14.838 & .000 \\
\hline & Subjective Well Being & .149 & .206 & .039 & .724 & .469 \\
\hline & Stress & -.474 & .235 & -.111 & -2.018 & $.044^{*}$ \\
\hline & Dietary Habits & .275 & .140 & .097 & 1.971 & $.049^{*}$ \\
\hline & Snack Intake & -.034 & .129 & -.013 & -.262 & .793 \\
\hline & Nutrition Label Awareness & .390 & .101 & .193 & 3.854 & .000 \\
\hline & $\begin{array}{l}\text { Nutrition Label Purchase } \\
\text { Behaviors }\end{array}$ & .018 & .060 & .015 & .305 & .761 \\
\hline \multicolumn{7}{|c|}{$K^{=.252,} R^{2=.064, \text { Adjusted }} R^{2=.049, F=4.454, p=.000^{\text {wotk }}}$} \\
\hline
\end{tabular}

\section{Discussion}

The present study inquired into and examined the effect of dietary habits, snack intake forms, and stress on the subjective oral health status of university students. By investigating the effect of awareness and stress on dietary habits and oral health in accordance with student food intake behaviors, and by recognizing the change in dietary habits and importance of dietary habits, the study attempted to find out the factors affecting oral health. Subject data consisted of oral health status and oral health awareness inquiries via surveys and the SPSS 20.0 statistics program. The study targeted a total of 400 subjects including $182(45.5 \%)$ males and $218(54.5 \%)$ females. The results of the study revealed that, in terms of the relationship between student dietary life and stress on the one hand and oral health status on the other, that stress was lower when subjective well being was higher, and that snack intake was higher and oral health status was worse when stress was higher. In other words, student oral health status was predicted to be better when stress was lower, dietary habits better, and nutrition label awareness was higher. College is a transitional stage between adolescence and adulthood, so it is important to establish adequate nutrition intake and dietary habits. University students can choose foods that fit their oral health status and needs by actively using nutrition labels because dietary habits different from adolescence may become established due to the sudden change in their environment, so an adequate education must be conducted to fill in the lacking nutrients.

In terms of the relationship between student dietary life and stress on the one hand and oral health status on the other, stress was lower when subjective well being was higher, and snack intake was higher and oral health status was worse when stress was higher. In other words, student oral health status was predicted to be better when stress was lower, dietary habits better, and nutrition label awareness higher.

College is a transitional stage between adolescence and adulthood, so it is important to establish adequate nutrition intake and dietary habits. University students can choose foods that fit their oral health status and needs by actively using nutrition labels because dietary habits different from adolescence may become established due to the sudden change in their environment, so an adequate education must be conducted to fill in the lacking nutrients.

Student oral health awareness and forms appeared to differ depending on the general characteristics of the subjects, so oral health education must consider these differences before being carried out. Due to the low awareness toward participation in oral knowledge and education, the consequent education regarding it must be strengthened.

Therefore, in order to achieve proper oral management and tooth preservation, oral health education for university students must be strengthened, and furthermore, thorough education must be conducted during childhood and the grade school years when most of the oral health management habits become established.

\section{References}

[1]. GR. Kim, M. Kim and YS. Kim, Undergraduates' oral health knowledge, attitude, and behavior relative to Oral health education, Journal of Korean Academy of Oral Health, .34(2), 2010, 178-186.

[2]. SY. Kim, JR Lee and MS Choi, Oral Health and Stress of College Women in Some Areas, Journal of Dental Hygiene Science, 5(4), 2015, 503-508.

[3]. HJ. Park, HW. Kim, SY. Ko and JH. Lee, Moderating Effects of Oral Health Behaviors on the Relation Between Daily Stress and Oral Health Status in Korean Adolescents, Korean public health research, 41(1), 2015, 81-93.

[4]. SJ. Kim and BJ. Lee, A association between self-reported oral health and oral health status among Korean male soldiers aged 18-24, Journal of Korean Academy of Oral Health, .36(4), 2012, 282-288.

[5]. SJ. Kim and IS. Park, A Study of Oral Health Recognition and Behaviors of College Students, Journal of Korean Academy of Dental Hygiene, .15(2), 2013, 89-100. 